\title{
Electrochemical Behavior of Jasmine Tea Extract as Corrosion Inhibitor for Carbon Steel in Hydrochloric Acid Solution
}

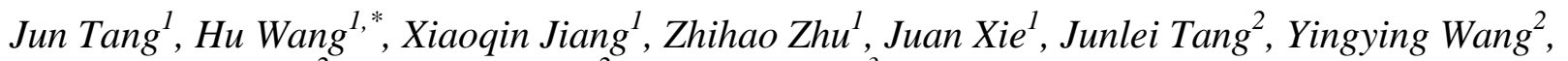 \\ Mohamad Chamas ${ }^{2}$, Yuanqiang Zhu', Hongguo Tian ${ }^{3}$ \\ ${ }^{1}$ School of Materials Science and Engineering, Southwest Petroleum University, Chengdu 610500, \\ China \\ ${ }^{2}$ School of Chemistry and Chemical Engineering, Southwest Petroleum University, Chengdu 610500, \\ China \\ ${ }^{3}$ Power Workshop, Refining \& Chemical Plant of Yumen Oilfield Company, Yumen 735200, China \\ *E-mail: senty78@126.com
}

doi: $10.20964 / 2018.04 .41$

Received: 21 November 2017 / Accepted: 29 January 2018 / Published: 6 March 2018

The extract of jasmine tea was studied as corrosion inhibitor for carbon steel in $1 \mathrm{~mol} \mathrm{~L}^{-1} \mathrm{HCl}$ solution by electrochemical method, scanning electron microscope (SEM) and X-ray photoelectron spectroscopy (XPS). Inhibition efficiency for carbon steel in $\mathrm{HCl}$ solution increases with inhibitor concentration and temperature. Adsorption behavior of the extract obeys Langmuir adsorption isotherm. Polarization curves results indicate that this extract is a mixed type inhibitor. SEM and XPS reveal that the extract adsorbs on metal surface and forms a protective layer.

Keywords: corrosion inhibitor, EIS, XPS, carbon steel, acid solution

\section{FULL TEXT}

(C) 2018 The Authors. Published by ESG (www.electrochemsci.org). This article is an open access article distributed under the terms and conditions of the Creative Commons Attribution license (http://creativecommons.org/licenses/by/4.0/). 